\title{
A 42 day tapering course of dexamethasone reduced duration of assisted ventilation in very low birthweight infants, but increased risk of cerebral palsy at age 1 year
}

Kothadia JM, O'Shea TM, Roberts D, et al. Randomized placebo-controlled trial of a 42-day tapering course of dexamethasone to reduce the duration of ventilator dependency in very low birth weight infants. Pediatrics 1999 Jul;104:22-27.

O'Shea TM, Kothadia JM, Klinepeter KL, et al. Randomized placebo-controlled trial of a 42-day tapering course of dexamethasone to reduce the duration of ventilator dependency in very low birth weight infants: outcome of study participants at 1-year adjusted age. Pediatrics 1999 Jul;104:15-21.

QUESTION: Among very low birthweight infants, does a 42 day course of dexamethasone reduce duration of assisted ventilation and affect developmental outcome at age 1 year?

\section{Design}

Randomised (allocation concealed*), unblinded, placebo controlled trial with follow up at age 1 year.

\section{Setting}

2 neonatal intensive care units (NICUs) in North Carolina, USA.

\section{Patients}

118 infants (53\% boys, $61 \%$ white) who were $15-25$ days old and had birth weight $<1501 \mathrm{~g} ;<10 \%$ decrease in ventilator settings for the previous 24 hours and fraction of inspired oxygen $\left(\mathrm{FIO}_{2}\right) \geqslant 0.3$; no clinical signs of sepsis; and no echocardiographic evidence of patent ductus arteriosus. 95 infants $(81 \%)$ survived to 1 year adjusted age; 93 of these surviving infants completed follow up.

\section{Intervention}

57 infants were allocated to dexamethasone, $0.25 \mathrm{mg} / \mathrm{kg}$ twice each day for 3 days, then $0.15 \mathrm{mg} / \mathrm{kg}$ twice each day for 3 days, then a 10\% reduction in dose every 3 days until a $0.1 \mathrm{mg} / \mathrm{kg}$ dose was reached on day 34 ; after 3 days on this dose, $0.1 \mathrm{mg} / \mathrm{kg}$ every day until 42 days after study entry. 61 infants were allocated to placebo. Dexamethasone and placebo were given intravenously or enterally.

\section{Main outcome measures}

Main outcomes related to initial hospital stay included number of days on assisted ventilation and on supplemental oxygen. At 1 year adjusted age, outcomes included survival, cerebral palsy, and neurological abnormality (cerebral palsy or hypotonia).

\section{Main results}

Infants who received dexamethasone had fewer days on assisted ventilation (median $13 \vee 25 \mathrm{~d}, \mathrm{p}=0.005$ ) and fewer days on supplemental oxygen (median $59 v 100 \mathrm{~d}$, $\mathrm{p}=0.03$ ) than did infants who received placebo. The groups did not differ for survival at 1 year adjusted age $(88 \%$ v $74 \%, \mathrm{p}=0.07)$. Surviving infants $(\mathrm{n}=93)$ who received dexamethasone were more likely to be diag-

Dexamethasone v placebo in very low birthweight infants $†$

\begin{tabular}{cllll}
$\begin{array}{l}\text { Outcomes at } \\
\text { age 1 year }\end{array}$ & $\begin{array}{l}\text { Dexa- } \\
\text { methasone Placebo }\end{array}$ & $\begin{array}{l}\text { RRI } \\
(95 \% \mathbf{C l})\end{array}$ & $\begin{array}{l}\text { NNH } \\
\text { (CI) }\end{array}$ \\
\hline Cerebral palsy & $35 \%$ & $11 \%$ & $\begin{array}{l}219 \% \\
(36 \text { to } 685)\end{array}$ & $\begin{array}{l}5 \\
(3 \text { to } 14)\end{array}$ \\
\hline $\begin{array}{c}\text { Neurological } \\
\text { abnormality }\end{array}$ & $42 \%$ & $18 \%$ & $\begin{array}{l}134 \% \\
(19 \text { to } 380)\end{array}$ & $\begin{array}{l}5 \\
(3 \text { to } 19)\end{array}$ \\
\hline
\end{tabular}

†Abbreviations defined in Glossary; RRI, $\mathrm{NNH}$, and $\mathrm{Cl}$ calculated from data in article. nosed with possible or definite cerebral palsy or neurological abnormality (table); similar results were obtained after adjusting for major cranial abnormality.

\section{Conclusion}

Among very low birth weight infants, a 42 day tapering course of dexamethasone reduced duration of assisted ventilation and time on supplemental oxygen; however, at 1 year adjusted age, infants who had received dexamethasone were more likely to be diagnosed with cerebral palsy and neurological abnormality.

* Information provided by author.
Source of funding for study by O'Shea et al: North Carolina Department of Environment, Health, and Natural Resources.

For correspondence. Dr TM O'Shea, Department of Pediatrics, Wake Forest University School of Medicine,

Medical Center Boulevard, Winston-Salem, $N C$ 27157, USA.Fax +1 3367162525 .

\section{COMMENTARY}

The study reported by Kothadia $e t a l$ and O'Shea $e t a l$ is the first large randomised trial to look at both the short term and 1 year outcomes of a 42 day regimen of dexamethasone for the prevention of chronic lung disease in premature infants. The findings of reduced duration of ventilator and oxygen dependency are consistent with those of a similar study ${ }^{1}$ and those in studies examining shorter regimens. ${ }^{2-3}$ The finding of an increased risk of cerebral palsy at 1 year adjusted age is supported by Yeh $e t a l^{4}$

One of the strengths of this study is that, unlike other studies, none of the infants in the placebo group was allowed to cross over into the treatment group and receive dexamethasone. Limitations of the study include the sample size of 118, which was the size needed to detect a difference in ventilator dependency. This sample size may have been inadequate to detect a significant difference in outcomes such as survival. Although the groups did not differ for survival at 1 year, the $\mathrm{p}$ value approached significance $(p=0.07)$. Thus, the study might have had inadequate power to detect an actual survival difference between groups; such a difference could partly explain the excess rate of cerebral palsy in the dexamethasone group (ie, dexamethasone increased survival of infants who were at high risk of developing cerebral palsy). The dosing regimen used in this study may differ from that used in other NICUs and could possibly limit the generalisability of the findings. More infants in the dexamethasone group were exposed to antenatal steroids than in the placebo group $(48 \% v 16 \%)$. It is unclear whether this difference may have played a role in the outcome of this study.

Despite its limitations, this study clearly raises concern about the long term effects of dexamethasone. The number needed to harm is 5 , which indicates that if 5 infants receive this regimen of dexamethasone, 1 additional infant will develop cerebral palsy or neurological abnormality. Further randomised controlled trials are needed to examine the short and long term risks and benefits of dexamethasone with respect to lower doses, shorter courses, and timing of treatment initiation.

Debbie Fraser Askin, RNC, MN Assistant Professor, Faculty of Nursing University of Manitoba

Winnipeg, Manitoba, Canada

1 Cummings JJ, D'Eugenio DB, Gross SJ. N Engl J Med 1989;320:1505-10.

2 Bhuta T, Ohlsson A. Arch Dis Child Fetal Neomatal Ed 1998;79:F26-33.

3 Halliday HL, Ehrenkranz RA. (Cochrane Review, latest version 24 Nov 98). In: Cochrane Library. Oxford: Update Software.

Yeh TF, Lin YJ, Huang CC, et al. Pediatrics 1998;101:E7. 